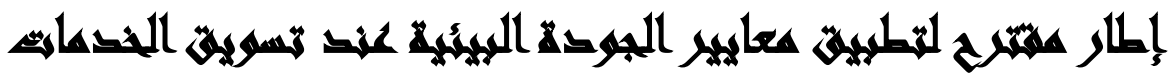

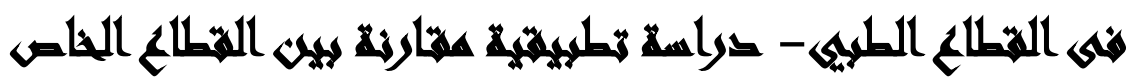 والمخالج العاه
}

[19]

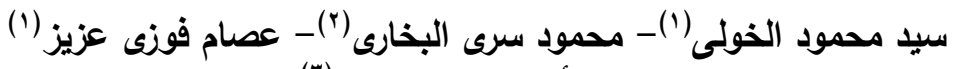

محمد أحمد خلاف محمد (r) (r)

( ) كلية التجارة، جامعة عين شمس r) معهد الدراسات والبحوث البيئية، جامعة عين شمس البمس

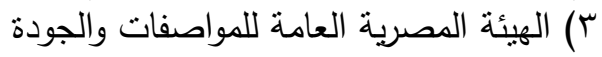

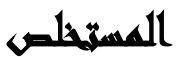

يعد القطاع الصحي من القطاعات الخدمية الهامة والتى تتمنل فى قطاع الثئئن الوقائية

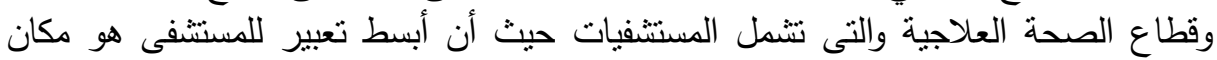

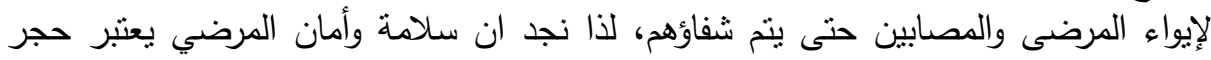

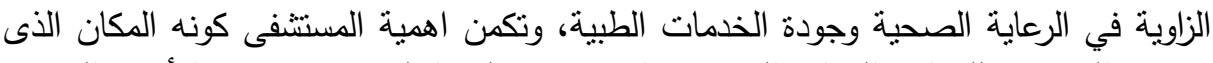

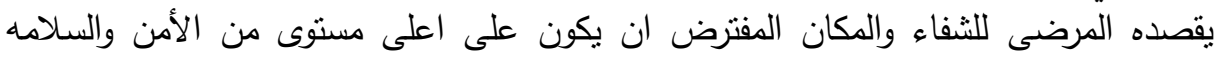

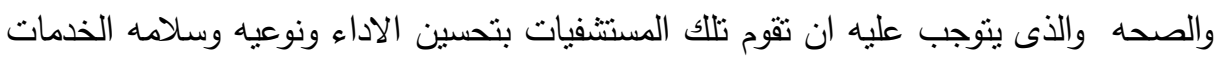

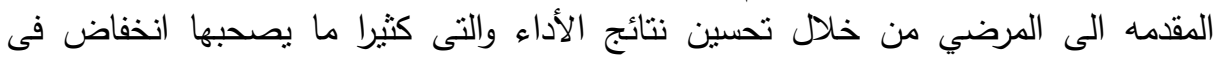
معدلات الاصابه بالعدوى بين المرضى والعاملين وقلة الأخطاء الطبيه والفنيه والنتخيصية بها لإليا

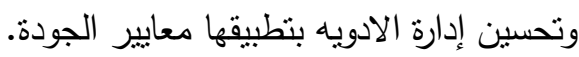

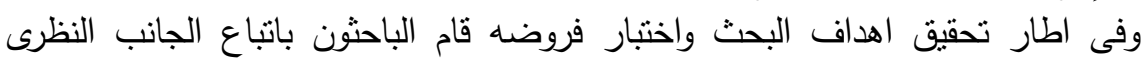

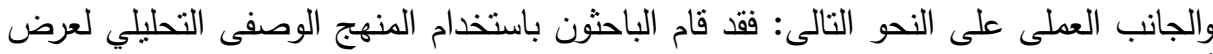

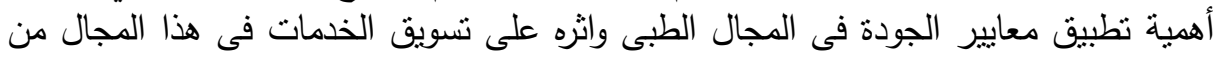

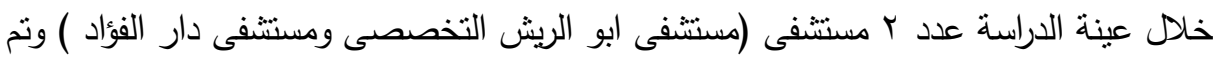

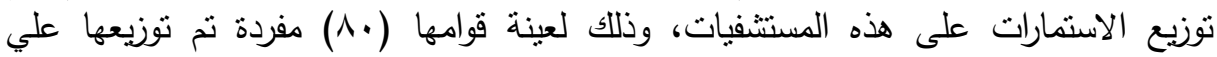

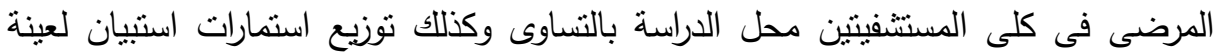

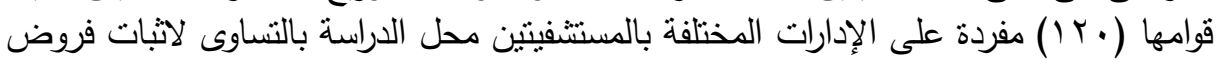

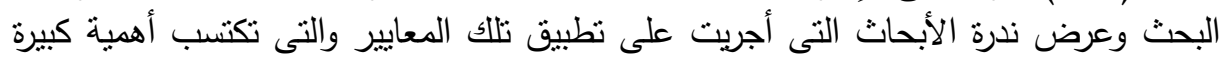

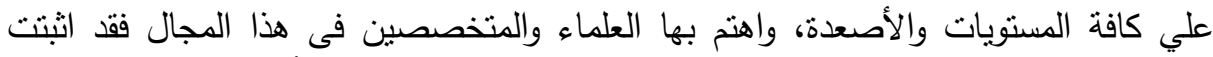

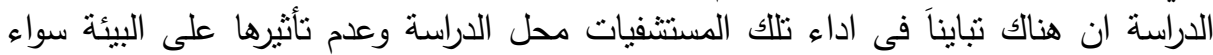
الداخلية أو الخارجية.

$$
\text { المجلد الثالث والثلاثون، الجزء الأول، يونيو 17 ب r }
$$




\section{المةهبه}

إن مـا يواجـه العـالم اليوم من مخاطر بيئية جسيمة، ومـا بطرأ فى هذا القرن الحسادي

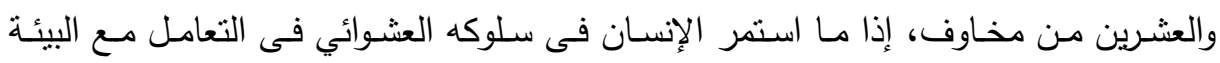

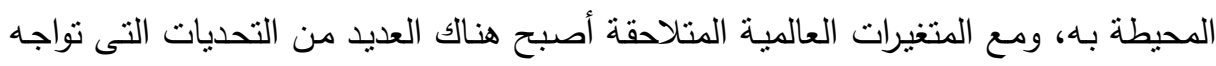

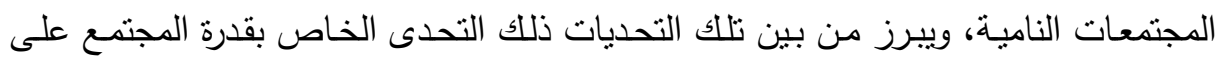

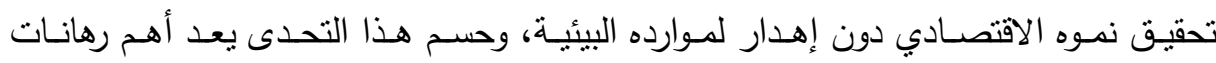
المستقبل بالنسبة للدول النامية في مسيرة التتمية الثاملة .

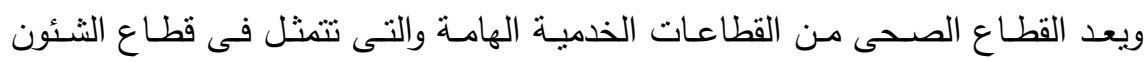
الوقائية وقطاع الصحة العلاجيـة وتعتبر جودة الرعايـة الصحية هـى درجـة الالتزام بمعايير

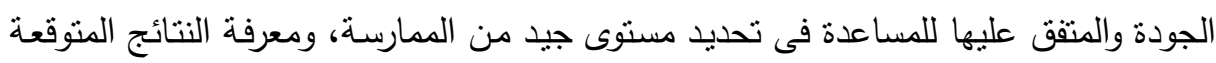
لخدمة أو إجراء أو تشخيص أو مشكلة طبيه معينة (بسيويي سالم)

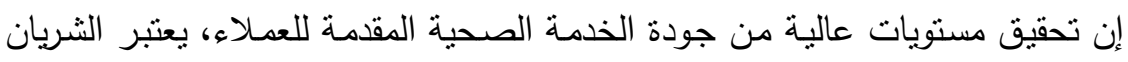

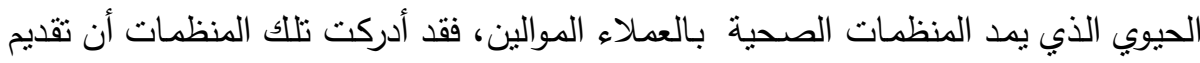

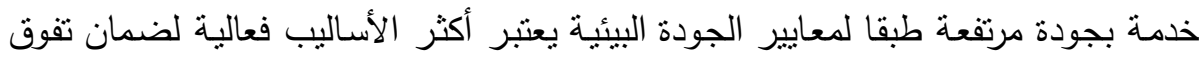

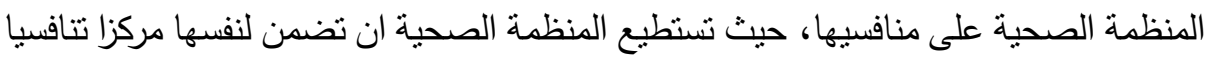

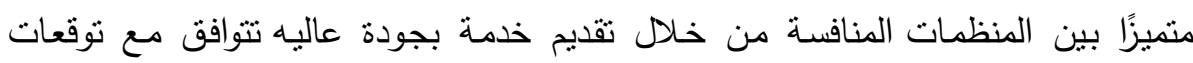

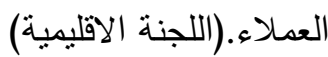

لذا نجد الفائدة التى تعود على المنظمـة الصحية عند الالتزام بمعايير الجودة البيئية (تحقيق وفرات الحجم فى إنتاج الخدمة . تحقيق وفرات الحجم فى البحوث والتطوير والتدريب .

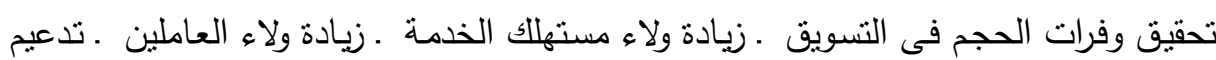

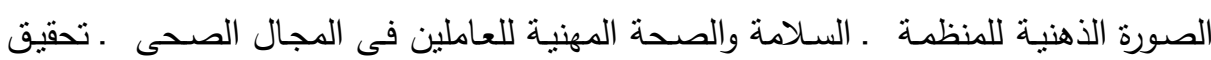
التنمية المستدامة).

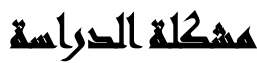


إن التزايد المستمر في عدد المستشفيات الخاصة والحكومية وادعاء البعض منها بتطبيق معايير الجودة البيئية بصورة شكلية وليس فعلية وزيادة نسبة الاهمال والتلوث البيئى داخل تلك المستشفيات وعدم وجود رقابة صارمة أدى بالضرورة الى تبنى الدولة إلى الاهتمام بالمستوى لهيه الصحي وإن أختلف ما تقدمه هذه المستشفيات من خدمات صحية للمواطنين

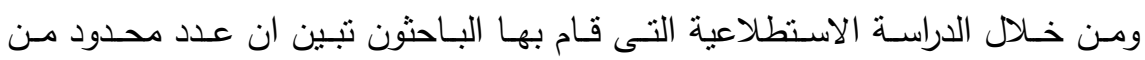
المستشفيات من يطبق معايير الجودة البيئية سواء من القطاع الحكومى مثل مستشفى دار الثفا تطبق معيار GCI ومعيار السياسة البيئية فقط، مستشفى السرطان OVOV تطبق معيار ومعيار السياسة البيئية ومعيار ISO 14001 GCI تطبق معايير الجودة فكانت مستشفى الجنزورى تطبق معيار GCI ومعيار السياسـة البيئية ومعيار OHSAS18001 فقط، ومستشفى القاهرة التخصصي تطبق معيار GCI ومعيار

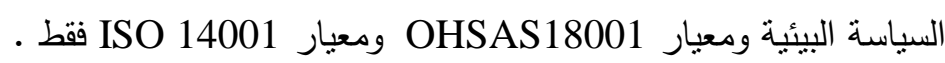
وحيث أن مظاهر الأففاق فى قطاع الصحة (المستشفيات) يهدف إلى تعظيم كفاءة وفاعلية جودة الخدمات المقدمة. وأساس تحقيق العوامل السابقة يتم من خلال تطبيق معايير الجودة على الخدمات، وهل يمكن قياس جودة الخدمات بعد نطبيق هذه المعايير وتأثز

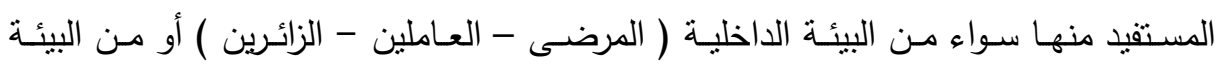

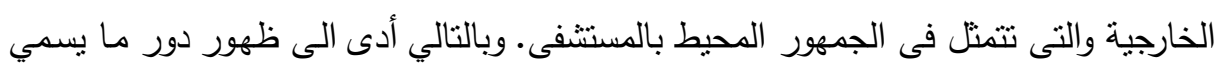
بتسويق الخدمات الصحية. وبناء على ما سبق يمكن توضيح مشكلة البحث في التساؤل الآتي:

\section{أسميلا الصوراما}

هل يوجد إطار لتلك المسنشفيات لتطبيق معايير الجودة البيئية عند نسويق الخدمات

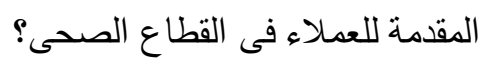




\section{أهساهنش التراسة}

تسعى هذه الدراسة إلى وضع إطار مقترح لتطبيق معايير الجودة البيئية عند نسويق الخدمات المقدمة للعملاء فى القطاع الطبي بدراسة تطبيقية مقارنة بين القطاع الطبى الخاص والقطاع الطبى العام من خلال تحقيق الأهداف التالية وهى:

1- قياس رضا العاملين والجمهور المحيط بالمستشفى من خلال معايير الجودة البيئية. r- نقييم تسويق الخدمات الحالية لتلك المستشفيات. r- إعداد تصور مناسب من خلاله يمكن ترشيد نسويق الخدمات لهذه المستشفيات.

\section{هغوضر التراسما}

ا. لا توجد علاقة جوهرية بين معايير الجودة البيئية وتسويق الخدمات فى المنظمة العلاجية r. لا توجد علاقة جوهرية بين معايير الجودة البيئية ورضا العملاء للمنظمة العلاجية.

\section{مجيتمع الصواسلة}

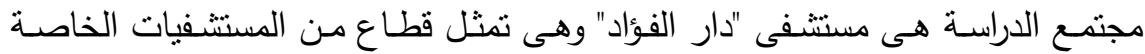
ومستشفي "أبو الريش الاستثمارى" وهى تمثل قطاع من المستشفيات التابعة للحكومة.

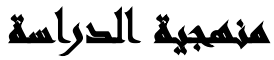

فى اطلـار تحقيق اهداف البحث واختبار فروضـه قام الباحث بأنباع الجانب النظرى

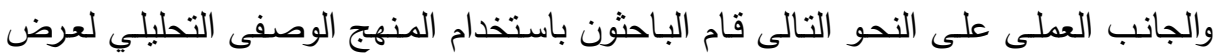

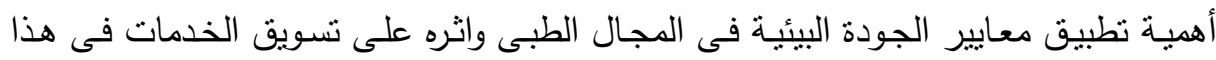
المجال، حيث يعتمد البحث على جزئيين الأول نظري و الثاني نطبيقي.

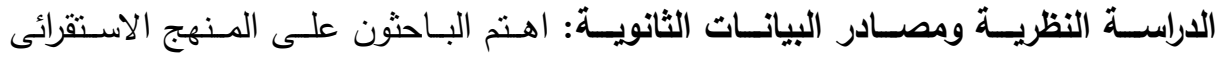
والاستتباطى فى هذه الدراسـة التى يقوم على تجميع وتحليل وتفسير المعلومـات المتعلقـة بالعناصر الرئيسية المكونـة للدراسـة وذلك عن طريق الاطـلاع على المراجع العلميـة العربيـة 
والأجنبية والدراسات السابقة الخاصة بموضوع البحث سواء في مجال معايير الجودة أو تسويق

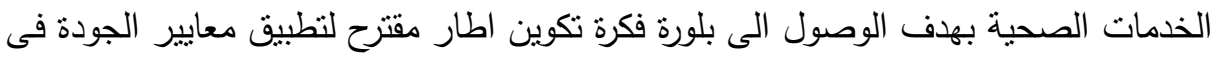
القطاع الطبي الدراسة الميدانية ومصادر البيانات الأولية: وقد اعتمد الباحثون فى الدراسة على عينـة من

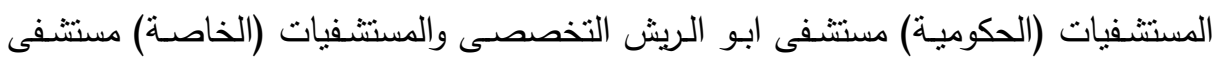

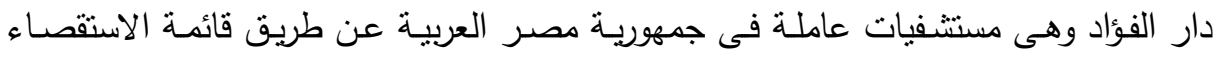

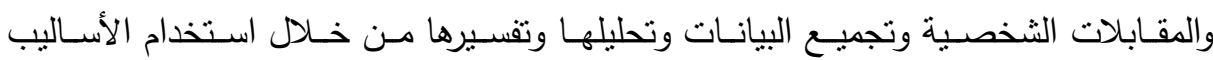
الإحصائية والرياضية الملائمة لطبيعة البيانات لتحقيق أهداف تلك الدراسة.

\section{أهمه التواسمة}

تتحصر أهيـة هذا البحث في تحديد الأثر المتبادل بين تطبيق معايير الجودة البيئية

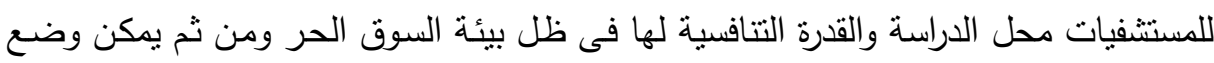
حلول وآليات لتزييل العقبات بهدف تطبيق معايير الجودة فى هذا المجال، وبالتالي الحفاظ علي العنصر البشرى من خلال وضع إطار مقترح لنطبيق معايير الجودة البيئية عند نسويق

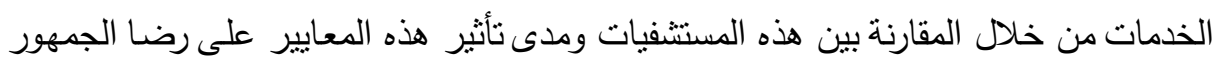

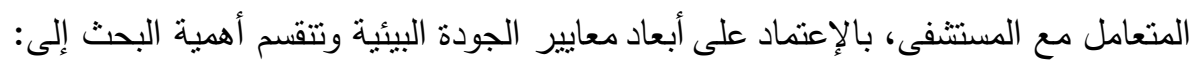

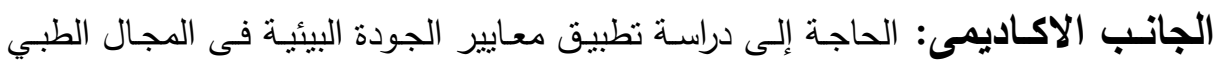
وأهيتها عند نسويق الخدمات واثر ذللك على القدرة التنافسية وإبراز الآثار المباثـرة وغير

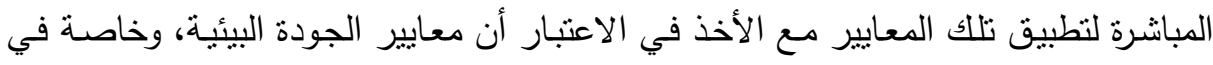
القطاع الصحى لم تحظ بنصيب وافر من الأبحاث. الجاتب التطبيقى: إن عدم تطبيق معايير الجودة فى المجال الصحى لها أثنار سلبية على العى البيئة و على صحة الإنسان 


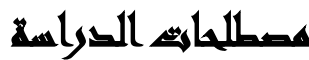

\section{وتثمل هذه الاراسة على عدة متغيرات أصلية مستقلة وهى:}

ا. معيار اعتماد المنشآت الصحية JCI : الاعتماد إجراء رسمي، يقوم به مجلس معترف بها.

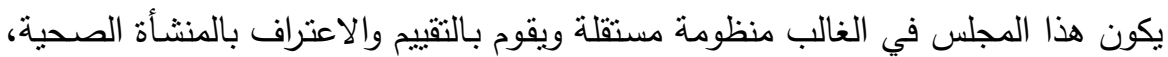
التي تقوم بنطبيق كافة المعايير التي وضعها. r. معيار نظم السـامة والصحة المهنية 18001 OHSAS : هى مواصفة دولية تعدل وصلية

على مساعدة المنشآت فى إتاحة نظام فاعل لإدارة السلامة والصحة المهنية بها

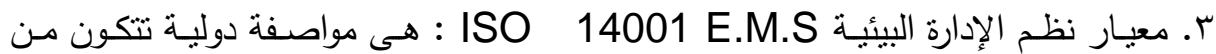
مجموعة من أنظمة الإدارة للتعامل مع الأبعاد البيئية لعمليات الإنتاج والمنتجات الئات ع. معيار سيجما Six Sigma : هو معيار دولى يسعى لتحسين جودة مخرجات العملية

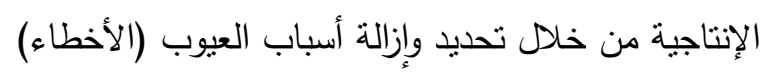
متغيرات تابعة: - n - تسويق الخدمات: وينقسم هذا المفهوم الى قسمين: التسويق: ويعنى تخطبط وتتفيذ عمليات نطوير وتسعير وترويج وتوزيع السلع والخدمات بغية خلق عمليات التبادل التي تحقق أهداف الأفراد والمنظمات" (حمدي الطائي واخرون) الخدمات: وهى تلك الأنشطة المعروفة وغير ملموسة

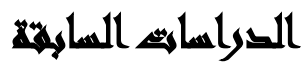

الدراسـات السـابقة على جانب كبير من الأهيـة فهى الإطـار المرجعى للباحثين الذى بستعينون بها كركيزة فى دراستة، وبالتالى سوف يتم تتاول عرض لتلك الدراسات واستتناجاتها حيث تساهم بشكل أساسى فى إختيار وتحديد مشكلة الدراسة، كما أنها تعين الباحث على على أن فئن يبدأ دراسته من حيث إنتهى الآخرين، والدراسات السابقة هى حجر الأساس الذئى ترتكز عليه

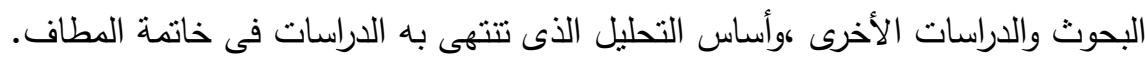


1 - دراسة خميس السليطى، ع . . ؟ :" قياس أثر جودة الخدمة الصحية على رضا المرضى دراسة تطبيقية على مراكز الخدمة الطبية بدولة قطر:

تتاول البحث بالدراسة والتحليل التعرف على مستويات الخدمات التى تقدمها مراكز الخدمة الطبية إلى جمهورها وظهور ما يعرف بجودة مستويات الخدمات المقدة وطرق وأساليب قياسها وذلك بهدف تحقيق أقصى درجات الرضا لدى الجمهور المستهدف لتلك الخدمات، ولقد كانت الخدمات الصحية فى طليعة الخدمات التى المستفادة من ذلك، وذلك نتيجة الثكاوى المتزايدة من قبل مستخدمى الخدمات الصحية ومطالبتهم المستمرة بالتطوير والتحديث لتالك الخدمات وتتوعها ووسائل تقديمها. التعليق: تتفق هذه الدراسة مع دراسة الباحث حيث ركزت على قياس أثز جودة الخدمة

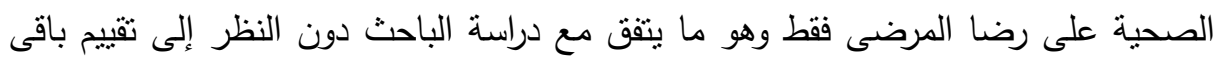
معايير الجودة وأثر ذلك على رضنا المرضى.

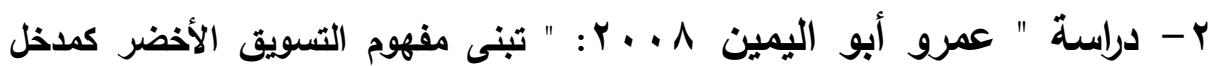
لتطبيق نظم إدارة الجودة البيئية 14001 ISO فى المنشآت القندقية ":

تتاولت هذه الدراسة اهتمام المشرعين وواضعي السياسات وصانعي القرارات بحماية البيئة على المستوى المحلى والعالمي وفلسفة الإدارة العليا بمنشآت الأعمال بتحويل منشآتهم صديقة للبيئة، والتسويق باعتباره المحرك الأول للنمو والتقدم من خلال ما بحققه من مستوى رفاهية

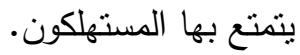
التعليق: تتفق هذه الدراسة مع دراسة الباحث في أن استخدام أساليب معالجة غير السليمة قد تتسبب في كوارث بيئية وأن ذلك بيطلب ضرورة الأخذ بنظام الإدارة البيئية 14001 ISO

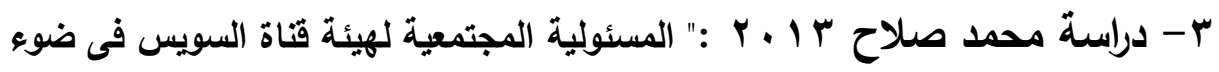

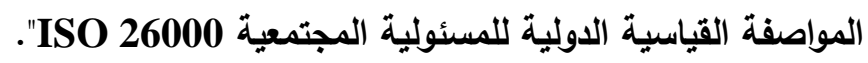

تتاولت هذه الدراسة واقع تطبيق معيار المسئولية المجتمعية على هيئة قناة السويس

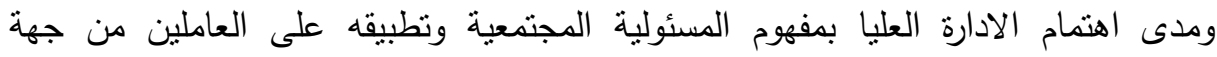
والجمهور المحيط بهيئة قناة السويس من جهة اخرى، ومدى الرضا من جانب المستفدين.

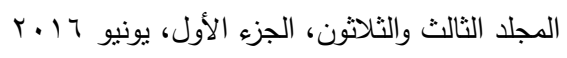


ISO التعليق: تتفق هذه الدراسة مع دراسة الباحث فى ان تطبيق معيار المسئولية المجتمعية اختيارية وتحمل فى جوهرها الجانب الادبى والمعنوى للمنظمة وان النطور الاقتصادى اجبر لهرئ المنظمات الكبيرة على تطبيقه واصبحت ميزة تتافسية بين تلك المنظمات. : Victor ( 2007 )

تتافش هذه الدراسة أهية وضع معايير للجودة البيئية يمكن الإهتداء بها فى مختلف

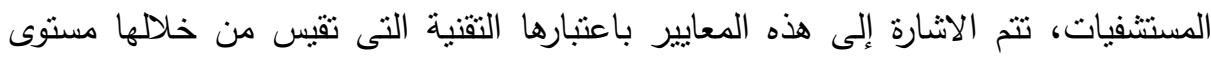
أدائها وفقاً للأوضاع المنلى، كما أنها تحدد كيف أن وصلت لهذه المستويات من الأداء بالإضافة إلى أنها تستخدم المعلومات المتاحة لديها بغرض الارتقاء بمستوى أدائها، وقد يقيم المرضى داخل المستشفى مستوى الجودة مقارنة بالمعدلات السائدة على المستوى القومى . التعليق: تتفق هذه الدراسة مع دراسة الباحث في حيث ركزت على استخدام المعايير لتقييم أداء المستشفيات وهو النظام التقليدى إلا أنها لم نتظر إلى النظم الحديثة كاستخدام معيار Six sigma

\section{ه - دراسة ( Bush and Haydn(2008}

تهدف المقالة إلى أن فريق الباحثين التابعين لمدرسة الطب بجامعة جون هوبكينز فى

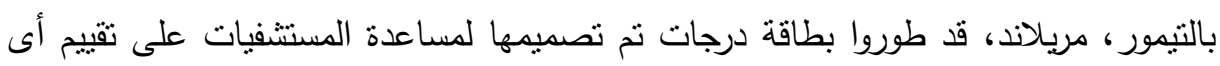

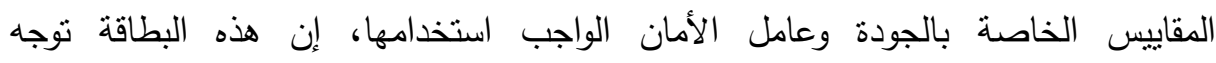

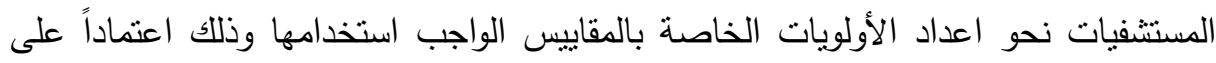

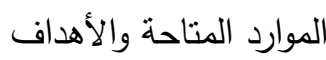
التعليق: تنفق هذه المقالة مع دراسة الباحث في أنها ركزت على اعداد نظام لتقييم الجودة

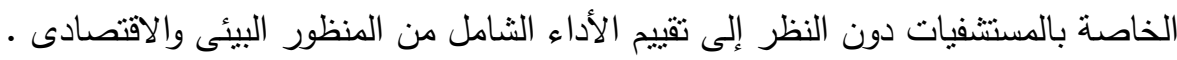




\section{الإطار العمليه للقواسلة}

قام الباحثون بالإطلاع على المراجع المختلفة والدراسات السابقة التي تعرضت من قريب او من بعيد لموضوع تطبيق معايير الجودة البيئية فى المجال الطبى وكذللك اهميتها عند

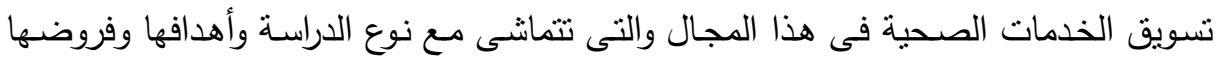
وهى:

ا. لا توجد علاقة جوهرية بين معايير الجودة البيئية وتسويق الخدمات فى المنظمة العلاجية.

r. ب لا توجد علاقة جوهرية بين معايير الجودة البيئية ورضا العملاء للمنظمة العلاجية. - المرحلة الأولى: تحديد موضوع القياس: تعد دراسة وتحليل المصادر والبيانات المختلفة التي أمكن الاعتماد عليها فى بناء استمارات الاستنيان من الأمور المهمة فى تحديد ونديد موضوع الدراسة، وتم تحديد موضوع القياس حيث حرص الباحثون وهو يعدون استمارات

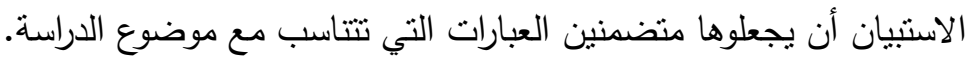

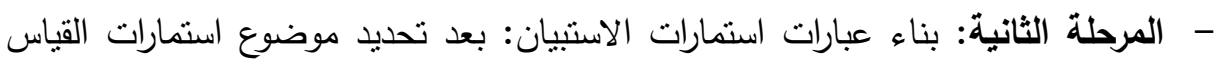

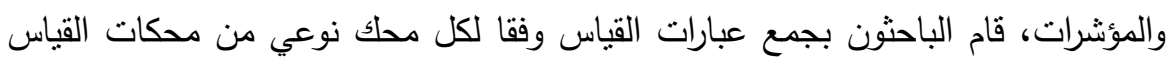

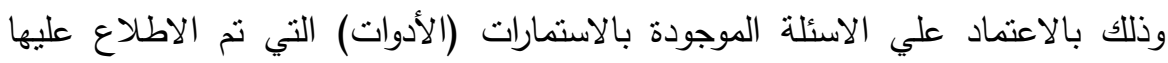
بجانب الاطار النظري للاراسة الحالية والدراسات السابقة في هذا المجال لذا استعان

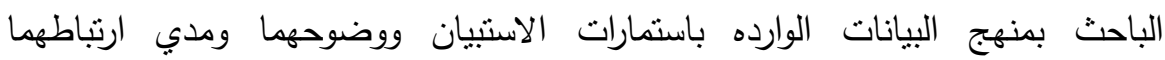
بالمؤشرات المراد قياسها، تم إعادة صياغة العبارات وتم إعداد استمارتين استبيان، وتم

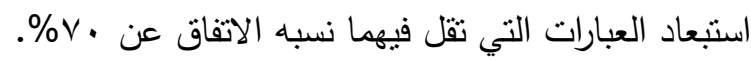
بنود الاستبيان: راعى الباحثون عند تصميم صحيفة الاستنيان:

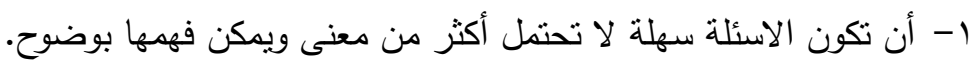

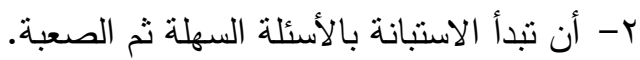
ץ- أن ينصب كل سؤال على جانب محدد. ع- تجنب الإكثار من عدد الأسئلة. ه- تجنب الأسئلة التي تتطلب إجابات مفتوحة 
مجلة العلوم البيئية

معهد الدراسات والبحوث البيئية - جامعة عين شمس لئه

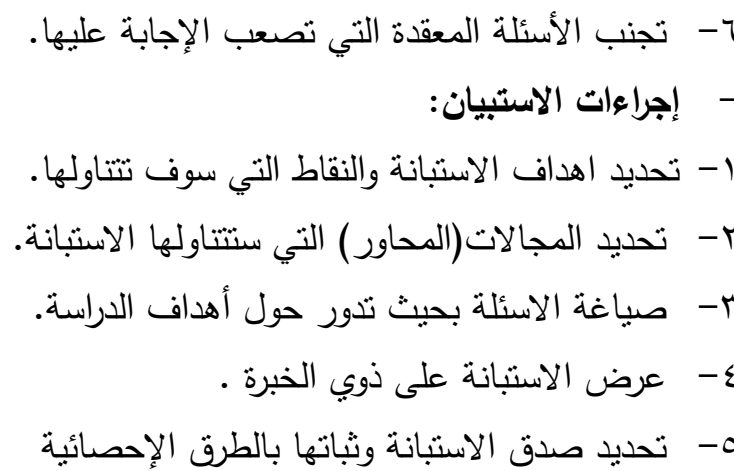

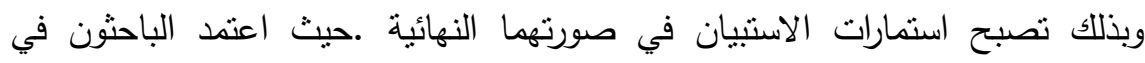

حساب الصدق العملي علي اجراءات التحليل الاحصائي والاساليب التي استخدامها في الاجابة علي فروض البحث وذللك لتحديد اجراءات واساليب التحليل الاحصائي وفقا لبرنامج الحزمه الاحصائية للعلوم الاجتماعية (spss) المعد لمركز الاحصاء جامعة عين شمس اذ نم استخراج التوزيعات التكرارية والنسب المئوية لكل عبارة في الأداء لكل متغير من متغيرات الاهديه

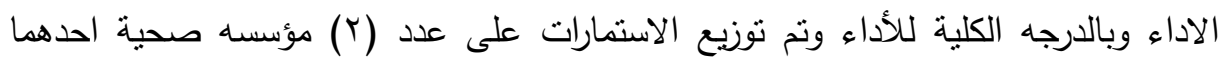

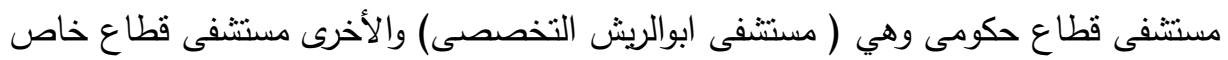

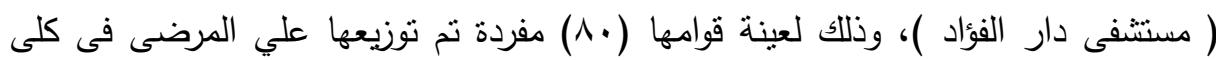

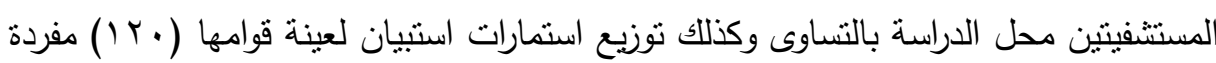

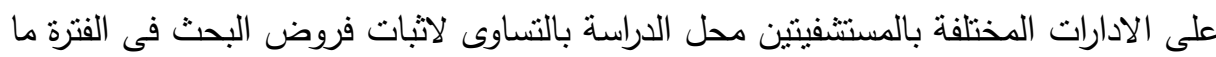

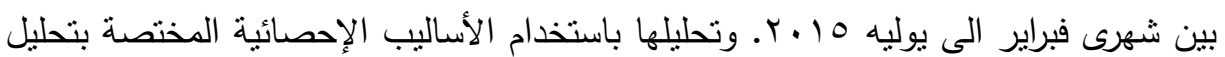
عناصر الاستبيان على النحو التالي: أولا: اختبار الثبات والصدق لأسئلة الاستبيان: إن الثبات يعنى استقرار القياس وعدم تتاقضة

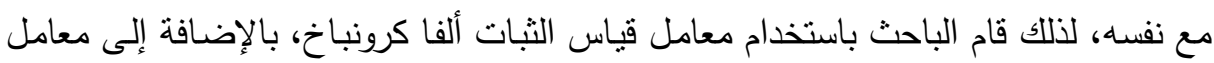

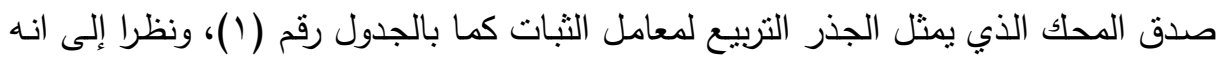

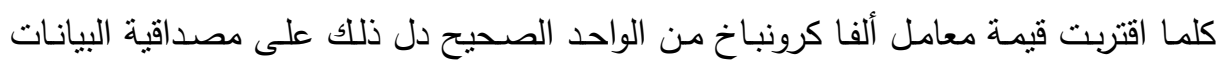

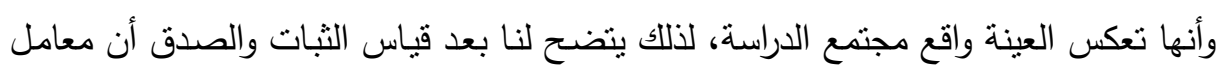




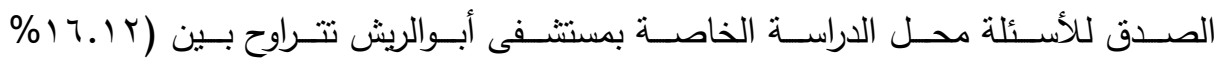

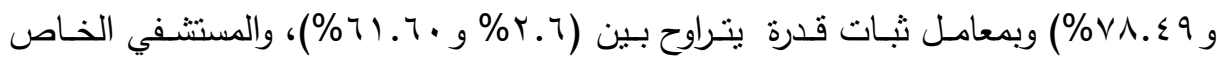

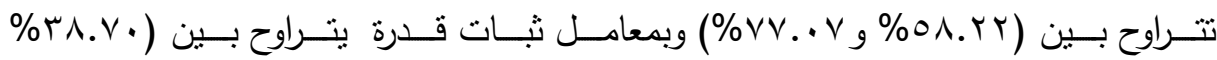

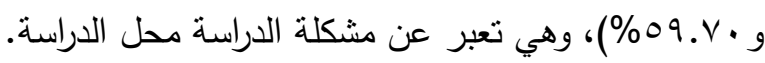
جدول رقم(1) : معامل قياس الصدق والثبات

المستشفى دار الفؤاد

\begin{tabular}{|c|c|c|}
\hline معامل الصدق & معامل الثبات & رمز المتغير \\
\hline$\% \vee \vee . \vee \vee$ & $\% \otimes 9 . \&$. & Y1 \\
\hline$\% \vee V . r \vee$ & $\% \circ 9 . \vee$. & y2 \\
\hline$\%$ \%r.ru & 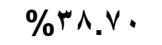 & $\mathrm{x} 1$ \\
\hline$\%$ \%०.YY & \%rr.q. & $x 2$ \\
\hline$\% 70.90$ & $\% \leqslant 4.0$. & $x 3$ \\
\hline$\% \vee \cdot .0$. & $\%$ \% . . . & $\mathrm{X} 4$ \\
\hline$\%$ \%V.Vo & $\% \leqslant 0.9$. & $\mathrm{x} 5$ \\
\hline
\end{tabular}
مستشفى أبو الريش

\begin{tabular}{|c|c|c|}
\hline معامل الصدق & معامل الثبات & رمز لمتغير \\
\hline$\% 0 \leq \leq \leq 1$ & $\%$ \% 9.7. & Y1 \\
\hline$\% 01 . \mathrm{\mu}$ & \%Yч.\&. & y2 \\
\hline \%тr.าะ & $\% \leq \cdot .0$ & $\mathrm{X} 1$ \\
\hline$\% \leq \varepsilon . r V$ & $\% 19.7$. & $\mathrm{x} 2$ \\
\hline$\% \circ V . O r$ & $\%$ \%r.l. & X3 \\
\hline$\% \vee \wedge . \leqslant q$ & $\% 71.7$. & $\mathrm{X} 4$ \\
\hline$\% 17.14$ & $\%$ \%. . . & $\times 5$ \\
\hline
\end{tabular}

ثانيا : مقياس ليكرت الخماسي لمعرفة اتجاهات أراء المستجيبين: يتضح لنا أن قياس محور

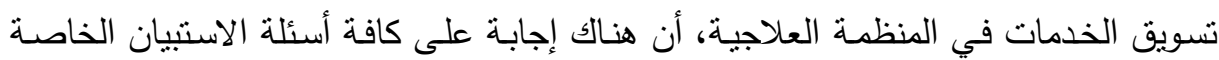

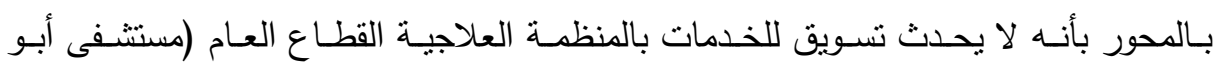

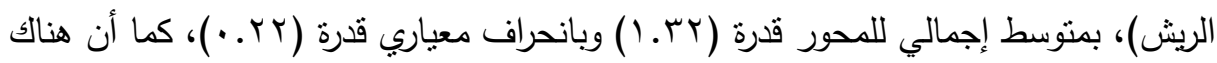

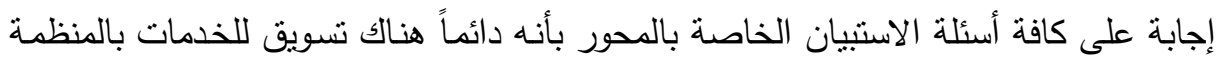
العلاجيـة بالقطـاع الخـاص، بمنوسط إجمـالي للمحور قدرة (T/.V. ) وبـانحراف معياري قدرة

ثُالثاً: معامل الارتباط بين المحاور الرئيسية للاراسة: يستخدم تحليل الارتباط في تقدير درجة الارنباط الخطي (مدى وجود علاقة خطية) بين المتغيرات المستقلة والمتغيرات التابعة محل الدراسة، ويتم اختبار معنوية معامل الارتباط من ذلك الافتراضات التالية: 


\section{الافتراض الأول:}

$H_{0}: p=0$

معامل الارتباط الخطي بين المتغير التابع والمتغير المسنقل غير معنوي عندما تكون (sig)

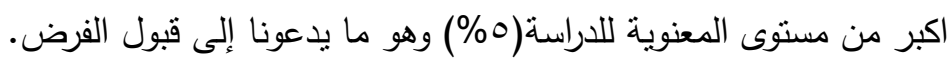
الافتراض الثاني : الثن من $H_{1}: p \neq 0$

معامل الارتباط الخطي بين المتغير التابع والمتغير المستقل معنوي عندما تكون (sig) اقل

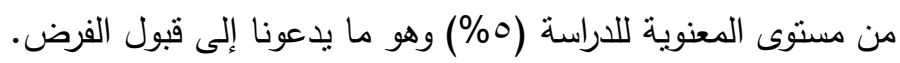

حيث قام الباحثون باستخدام معامل الارتباط بيرسون (Pearson)

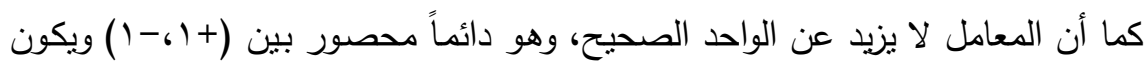
موجباً إذا كان الارتباط طردياً، وسالباً إذا كان عكسياً، وإذا كانت r=0 كان العان الارتباط منعدماً اى أن الظاهرتين مستقلتان عن بعضهما البعض. البراط. جدول رقم(ץ): معاملات الارتباط ومعامل التحديد بين المحاور الرئيسية للدراسة بمستشفي ابو بوضئ

\begin{tabular}{|c|c|c|c|c|c|c|c|}
\hline & & & & \multicolumn{4}{|c|}{ الريش } \\
\hline $\mathbf{R}^{2}$ & $\times 5$ & $x 4$ & $x 3$ & $x 2$ & $\mathrm{X1}$ & \multicolumn{2}{|l|}{ بيان } \\
\hline \multirow{2}{*}{$\% \circ v . r$} & $\% 10 \ldots-$ & $\% \circ 9 . v$. & \%rr.r. & $\%$ \% & $\%$ \% ..v. & قوة الارتباط & $\mathrm{Y1}$ \\
\hline & . ror & . & . & . &..$\leqslant 10$ & مستوي الدلالة & \\
\hline \multirow{2}{*}{$\% 71.9$} & $\% \cdot r$. & \%rr.\&. & $\%$ \%५... & $\%$ \%०1.r. & \%чr.т. & قوة الارتباط & $\mathrm{Y2}$ \\
\hline &. $.9 \wedge \mathrm{V}$ & $\ldots r$ & ...ro & . & $\ldots \ldots 9$ & مستوي الدلالة & \\
\hline
\end{tabular}

يوضـح لنا الجدول رقم (Y) علاقة الارتباط بين المتغيرات التابعة والمتغيرات المستقلة على النحو التالي: - محور تسويق الخدمات في المنظمة العلاجية يربط بقوة طردية مقدارها

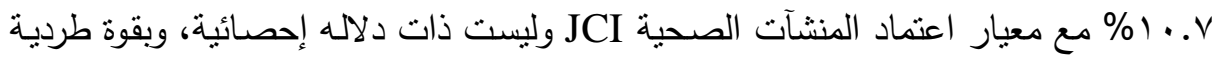

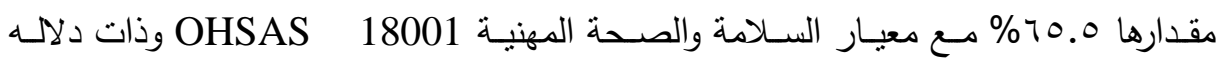

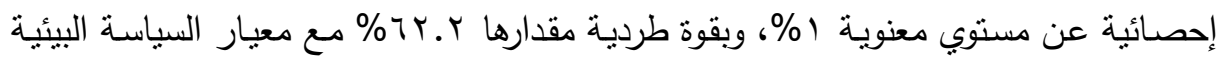

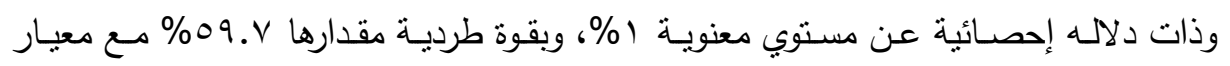


الإدارة البيئية ISO 14001 وذات دلالهـ إحصائية عن مستوي معنويـة ا \%، وبقوة عكسية مقدارها ه 0 \% مع معيار المسئولية المجتمعية ISO 26000 وليست ذات دلاله إحصائية.

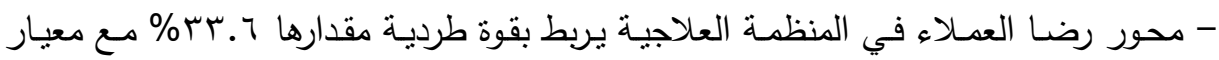

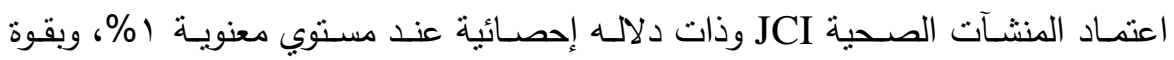

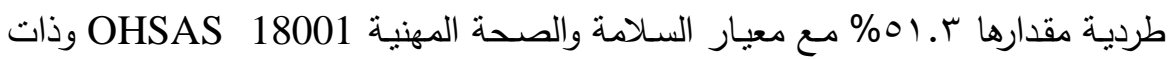

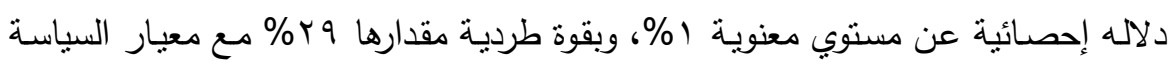

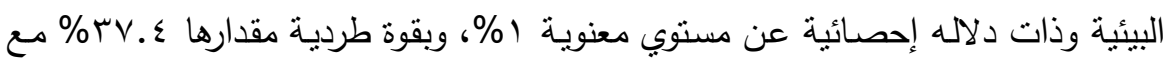

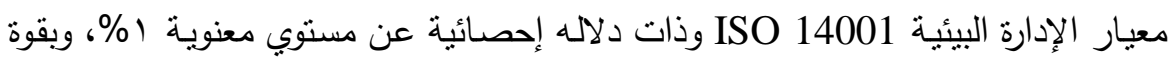

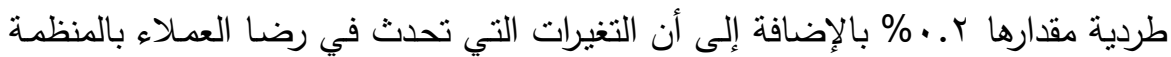
العلاجية تعود بنسبة 9 ـ آ٪\% إلى التغيرات التي تحدث في المتغيرات المستقلة. جدول رقم(ץ): معاملات الارتباط بين المحاور الرئيسية للاراسة بمستتفى دار الفؤاد

\begin{tabular}{|c|c|c|c|c|c|c|c|}
\hline $\mathbf{R}^{2}$ & $\times 5$ & $\mathrm{X} 4$ & $\mathbf{X 3}$ & $\mathbf{X 2}$ & $\mathrm{X} 1$ & \multicolumn{2}{|l|}{ بيان } \\
\hline \multirow{2}{*}{$\% \wedge \perp . V$} & $\% 10 . r$. & \%тr... & $\% \wedge . .9$. & $\%$ \%r.A. & 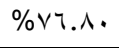 & قوة الارتباط & Y1 \\
\hline & $. r \leqslant V$ & . & - & $\cdots \vee \vee q$ & . & مستوي الدلالة & \\
\hline \multirow{2}{*}{$\% \wedge 4.9$} & $\% \leq \vee . r \cdot-$ & $\% \circ \wedge . r$. & \%Vr.r. & $\%$ \%... & $\% 70.0$. & قوة الارتباط & Y2 \\
\hline & . & . & . & $\therefore$.AVV & . & مستوي الدلالة & \\
\hline
\end{tabular}

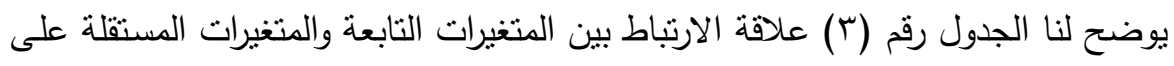
النحو التـالي: - محسور تسويق الخدمات في المنظمـة العلاجيـة يـربط بقوة طرديـة مقدارها

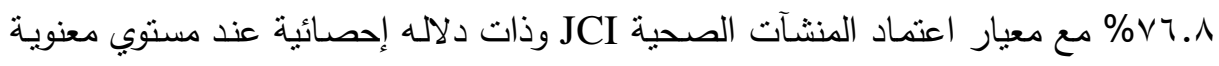

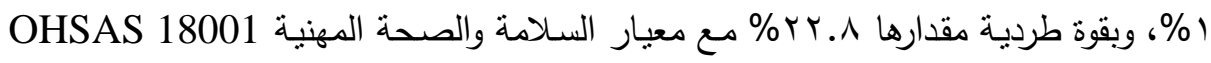

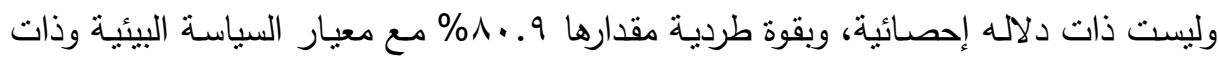

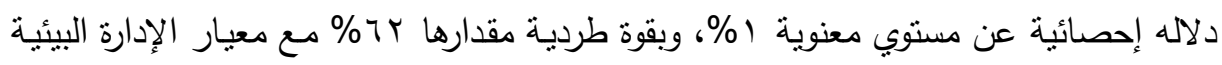

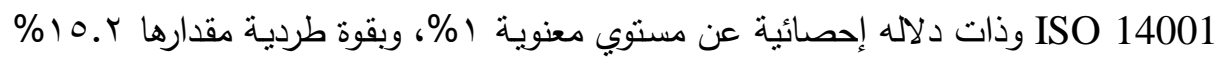

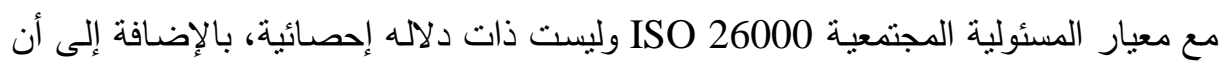




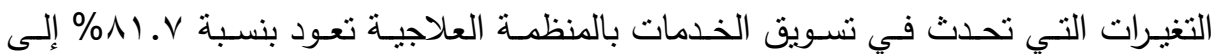
التغيرات التي تحدث في المتغيرات المستقلة. رابعاً: إجراء اختبار تحليل التباين الأحسادي(ANOVA): ويهدف الباحثون من إجراء هذا

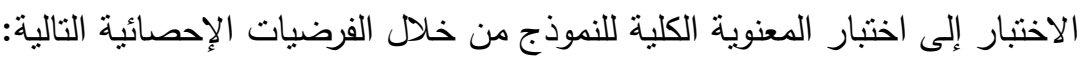

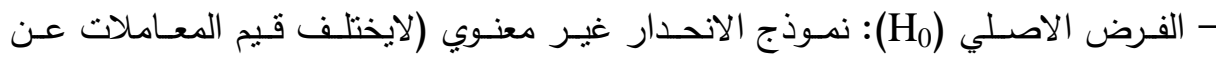
(الصفر ).

- الفرض العدمي (H1) : نموذج الانحدار معنوي (تختلف قيم المعاملات عن الصفر ). للتأكد من اختبار الاستقلالية بين المتغيرات المستقلة والمتغير التابع كما يلي: مستشفى أبو الريش:

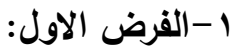

- الفرض الأصلي (H) :لا توجد علاقة معنوية بين المتغير التابع والمتغيرات المستقلة - الفرض البديل (H1): توجد علاقة معنوية بين والمتغيرات المستقلة للاراسة

\begin{tabular}{|c|c|c|c|c|c|}
\hline |الدلاكة & $\mathbf{F}$ & متوسط المريعات & درجات الحرية & مجموع المريعات & بيـان \\
\hline \multirow[t]{3}{*}{$\ldots \ldots$} & 17.291 & . ror & 0 & $1 . v 74$ & الانحدار \\
\hline & & $\ldots Y_{I}$ & $0 \leqslant$ & 1.1Tr & البواقي \\
\hline & & & 09 & r.A97 & الاجمالي \\
\hline
\end{tabular}

الجدول رقم (ع) يوضح لنا نتيجة مقارنة المتوسطات باستخدام اختبار (F) والذي يوضح

لنا وجـود دلالـة إحصـائية للعلاقة بين المتغير التابع (محور نسويق الخدمات) والمتغيرات

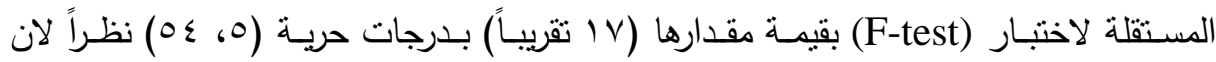
(05.>مستوي الدلالة)، وهو يدعونا إلى رفض الفرض الأصلي (Hos) وقبول الفرض البديل

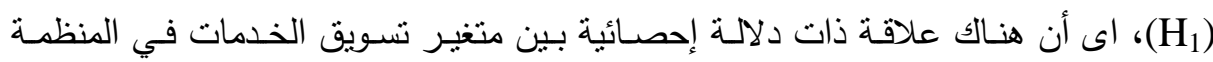




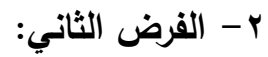

جدول رقم(•):

\begin{tabular}{|c|c|c|c|c|c|}
\hline الالالة & $\mathbf{F}$ & متوسط المربعات & درجات الحرية & مجموع المربعات & بيـان \\
\hline$\ldots \ldots$ & r &.$r 9 r$ & 0 & $1 . \Sigma 7 r$ & الانحدار \\
\hline & & $\cdots 10$ & $0 \leqslant$ & . .vAr & البواقي \\
\hline & & & 09 & $T . Y \leq T$ & جا \\
\hline
\end{tabular}

الجدول رقم (0) يوضح لنا نتيجة مقارنة المتوسطات باستخدام اختبار (F) والذي يوضح

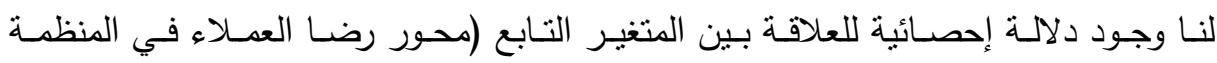

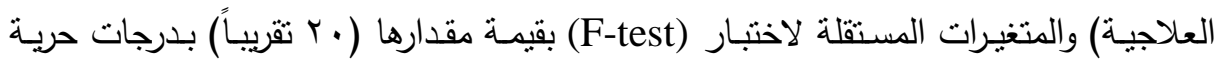

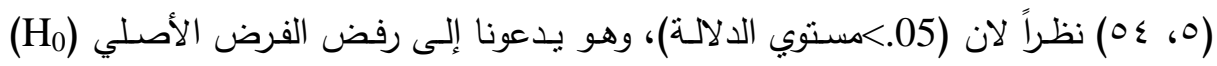

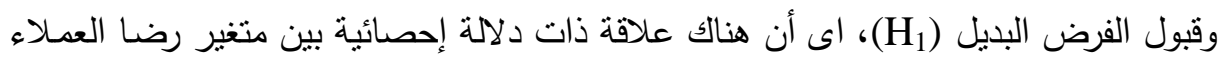
في المنظمة العلاجية والمتغيرات المستقلة. مستثفى دار الفؤاد: 1- الفرض الاول:

- الفرض الأصلي (Ho ) :لا توجد علاقة معنوية بين المتغير التابع والمتغيرات المستقلة - الفرض البديل (H1) : نوجد علاقة معنوية بين والمتغيرات المستقلة للاراسة

\begin{tabular}{|c|c|c|c|c|c|}
\hline الدلالة & $F$ & متوسط المربعات & درجات الحرية & مجموع المربعات & بيــان \\
\hline$\therefore \cdots$ & or.orv & $\cdot \leq \leqslant 1$ & 0 & $r . r \cdot \varepsilon$ & الانحدار \\
\hline & & $\because \cdots 1$ & $0 \leqslant$ & $\because \leq \leq 0$ & البو اقي \\
\hline & & & 09 & $r .7 \leq 9$ & الاجمالي \\
\hline
\end{tabular}

الجدول رقم (7) يوضح لنا نتيجة مقارنة المنتسطات باستخدام اختبار (F) والذي يوضح

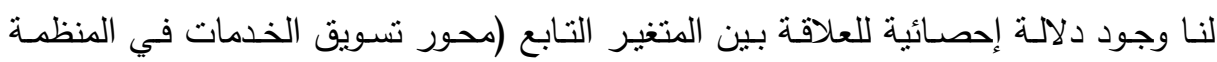

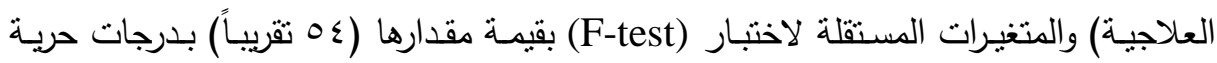

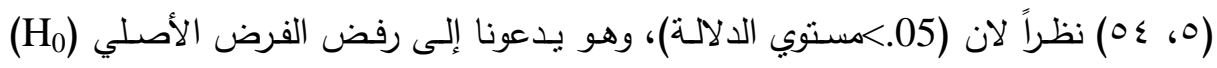




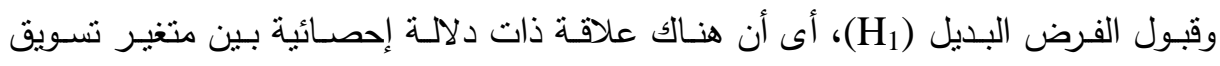
الخدمات في المنظمة العلاجية والمتغيرات المستقلة.

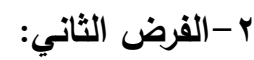

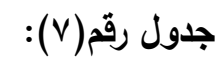

\begin{tabular}{|c|c|c|c|c|c|}
\hline الدلالة & $\mathbf{F}$ & متوسط المريعات & درجات الحرية & مجموع المربعات & بيـان \\
\hline$\ldots \ldots$ & VI. 510 & .0101 & 0 & $\cdot . \vee 7 V$ & الانحدار \\
\hline & & $\cdots r$ & $0 \leq$ & .0117 & البواقي \\
\hline & & & 09 & - .ANK & الاجمالي \\
\hline
\end{tabular}

الجدول رقم (V) يوضح لنا نتيجة مقارنة المتوسطات باستخدام اختبار (F) والذي يوضح

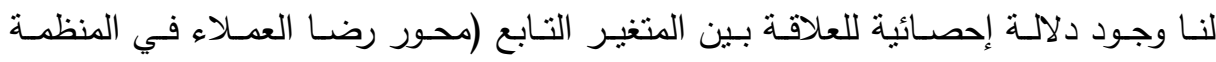

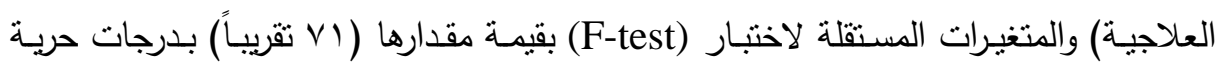
(0، ع 0) نظراً لان (05.>مستوي الدلالـة)، وهو يدعونا إلى رفض الفرض الأصلـي (H)

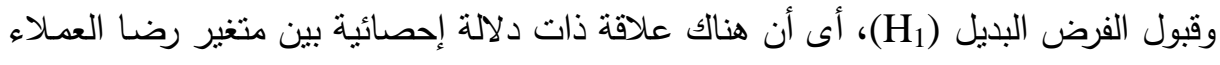
في المنظمة العلاجية والمتغيرات المستقلة.

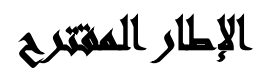

عناصر الإطار المقترح: (أ) الهدف من الإطار المقترح (ب) محتوي الإطار المقترح (ج) أسلوب تطبيق الإطار المقترح (أ)- الهدف من الإطار المقترح:

1-التعرف علي فرص إنتاج خدمة طبيه ذو جودة عاليه. r-تحديد الأسلوب الأنسب لكيفية تسويق الخدمات الصحية. r-تحديد الأسلوب الأنسب لكيفية استغلال الامكانيات المتاحة داخل المشفى. ع-تشجيع العاملين علي المشاركة لنطبيق معايير الجودة البيئية. 
(ب)- محتوي الإطار المقترح لتطبيق معايير الجودة البيئية: يتم وضع إطار مقترح لنطبيق

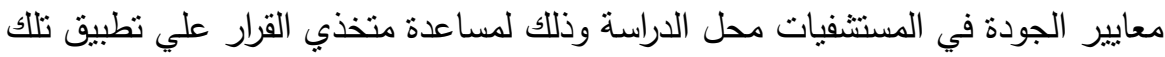

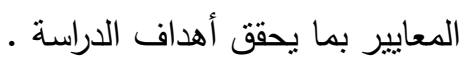

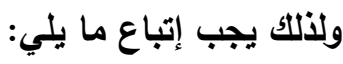

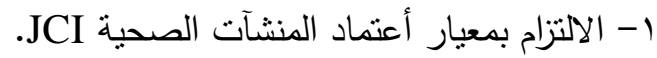
YHSAS أحدد الأنشطة والأهداف الخاصة بمعيار نظم السلامة والصحة المهنية

r- وضع اسلوب لنطبيق السياسة البيئية. ع- وضع برامج لنطبيق معيار نظم الإدارة البيئية ISO 14001 E.M.S وتحديد الفترة الزمنية لتنفيذ تلك البرامج.

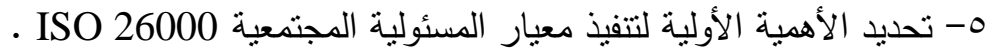
צ- تحديد إمكانية تتفيذ معايير سيجما Six Sigma ( الإدارة بدون أخطاء ).

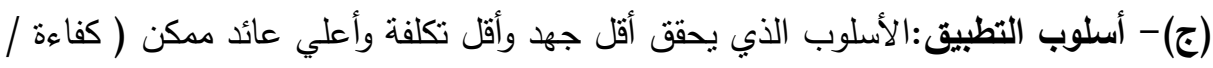

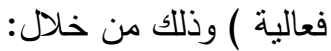
- وضع الخطط التنفيذية لكل نشاط على حدى. - التزام العاملين بمعايير للجودة للمساهمة في جودة الأداء. - الترتيب الداخلي للمستشفى بما يعمل علي عدم الاصابة بالعدوى او الامراض وخفض

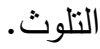
- التشجيع علي الإبتكار والتجديد. - زيادة المساحات الخضراء داخل وخارج المشفى. - تواجد اتصالات بين المريض والطبيب المعالج

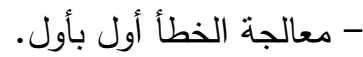
- توعية العاملين بمعايير الجودة البيئية وإنراكهم في إتخاذ القرارات. - تدريب العاملين علي الالتزام بمعايير الجودة البيئية. 


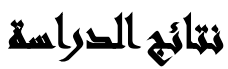

ا-تبين عدم تحقق الفرض القائل بأنه لا توجد علاقة جوهريـة بين معايير الجودة وتسويق

الخدمات فى المنظمة العلاجية.

r-تبين عدم تحقق الفرض القائل بأنه لا توجد علاقة جوهريـة بين معـايير الجودة ورضـا

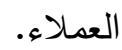

ب-نبين ان هناك عدد كبير من مستتفيات جمهورية مصر العربية تهمل الجانب النسويقي

$$
\text { لخدماتها وهذا يتفق مع (دراسة صالح عبد الله) }
$$

ع-تبين ان هناك عدد كبير من مستشفيات جمهوريـة مصر العربيـة تعتبر معيـار الجودة

ه من الرفاهية ولا تطبقه بشكل رسمى وهذا يتفق مع (دراسة محمد صلاح) ISO26000

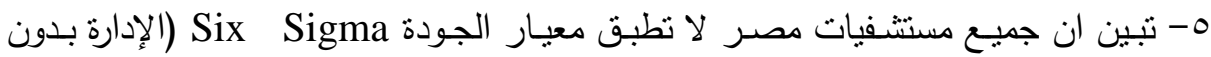

أخطاء)

צ- تبين عدم مراعاة بعد الجودة (JCI) عند التخطيط لإنشاء عدد كبير من المنشآت الصحية

$$
\text { وهذا يتفق مع (دراسة آزاد رؤوف) بئن }
$$

\section{اللزوكيامي}

ا . يجب ان يكون هنـاك اهتمـام أكبر ببعـد الجودة البيئية وإبـراز هذا البعد فـى الحمـلات الترويجية التى تقوم بها هذه المسنتشفيات. r. إجراء عملية نوعية بيئة من قبل هذه المستشفيات لمديريها لإدراك الوعي البيئي. r. الاهتمام بالصورة الذهنية للعملاء وخاصة للعملاء المرتقبين.

ع. يجب على المستشفيات تطبيق معيار الجودة Six Sigma (الإدارة بدون أخطاء)

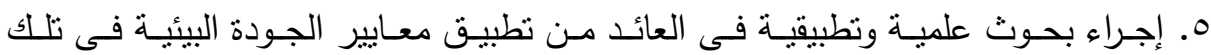

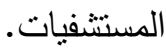




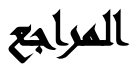

بسيويي سالم، مفهوم وهيكلة برنامج الاعتماد المصرى، المؤتمر العربي الثالث، الاتجاهات التطبيقية الحديثة في إدارة المستشفيات، تقنية نظم المعلومات، المنظمة العربية للتمية

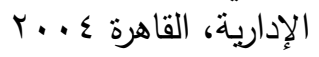

اللجنة الإقليمية لثرق المتوسط، المكتب الإقليمي،اعتماد المستشفيات ومؤسسات التعليم الطبي

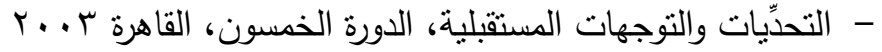

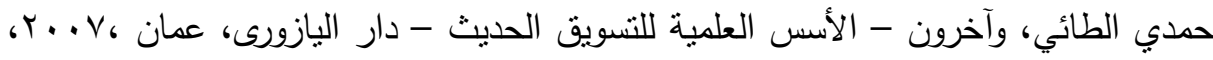

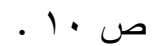

خميس حسن السليطي: " قياس أثز جودة الخدمة الصحية على رضا المرضى ( دراسة

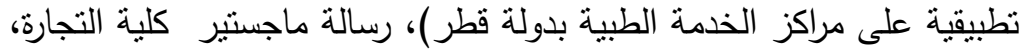

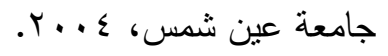

عمرو أبو اليمين: " ( تبنى مفهوم التسويق الأخضر كمدخل لتطبيق نظم إدارة الجودة البيئية ISO 14001

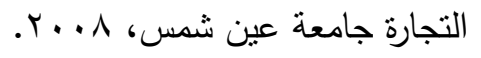

محمد صلاح الدين محمد يوسف: " المسئولية المجتمعية لهيئة قناة السويس فى ضوء

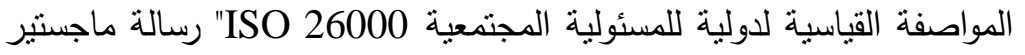

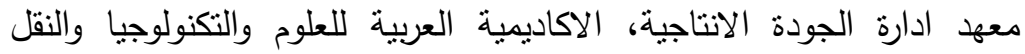

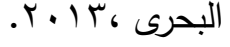

فرج عبد العزيز عزت: نظرية الاقتصاد القياسي، كلية التجارة جامعة عين شمس، || بـ،

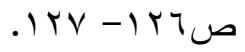

صالح عبد الهه " دور عناصر المزيج التسويقي الخدمي في زيادة الإقبال على الددارس الأهلية :

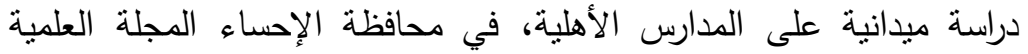

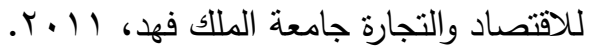

محمد صلاح الدين محمد يوسف " المسئولية المجتمعية لهيئة قناة السويس فى ضؤ المواصفة

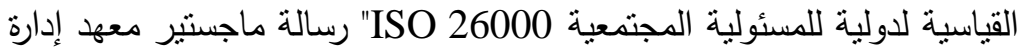

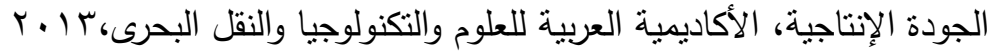

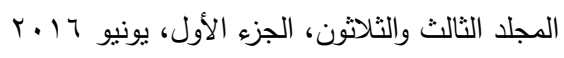


آزاد عطوف محمد رؤوف، "مدخل إلى الاعتبارات التخطيطية العامة للمستشفيات الحكومية

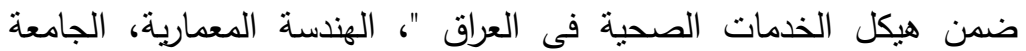

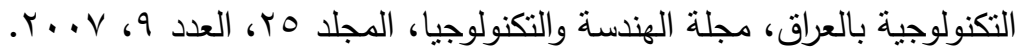

Sower, Victor E, "Benchmarking in Hospitals: More Than a Scorecard”, Quality Progress ; Aug, Vol. 40 Issue 8 ,2007.

Bush and Haydn, "Scorecard Urges Hospitals to Grade Quality Measures ", H\&HN: Hospitals \&Health Networks; Apr, Vol. 82 , Issue 4, 2008. 
سيد محمود الخولى وآخرون

\title{
A SUGGESTED FRAME TO APPLY \\ ENVIRONMENTAL QUALITY STANDARDS WHILE \\ MARKETING SERVICES IN MEDICAL SECTOR \\ AN APPLIED COMPARATIVE STUDY BETWEEN \\ PUBLIC AND PRIVATE SECTOR
}

El-khouly, S. M. ${ }^{(1)}$; El-Bukhari, M. S. ${ }^{(2)}$; Aziz, E. F. ${ }^{(1)}$

and Khalaf, M. A. ${ }^{(4)}$

1) Faculty of Commerce, Ain Shams University, 2) Institute of Environmental Studies \& Research Ain Shams University, 3) Egyptian Organiztion for Standardization \& Quality (Eos)

\begin{abstract}
The health sector of the important service sectors represented in therapeutic health sector, which includes hospitals, where the simplest expression of the hospital is a place to house the sick and injured until they are relieved of pain, so we find that the safety and security of patients is the cornerstone of health care and the quality of medical services, lies the importance of the hospital being the place where the patients are supposed to heal and place it meant to be at the highest level of security, safety and health and that it should be played those hospitals to improve performance and the quality and safety in the services provided to patients.

As part of achieving the goals of research and testing, the researchers followers of the theoretical side and side pragmatic as follows: - have the researchers using descriptive and analytical approach to show the importance of applying quality standards in the medical field and its impact on the marketing of services in this area through the study sample number 2 Hospital (Hospital Abu Rish Specialist Hospital Dar Al Fouad) were the forms distributed to these
\end{abstract}

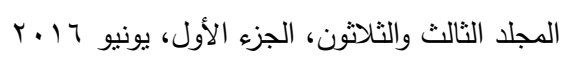


hospitals, and so strong for a sample (80) Single distributed to patients in hospitals under study equally as well as the distribution of the sample of questionnaires (120) Single various departments in hospitals under study equally to prove hypotheses and display the scarcity of research on the application of these standards, which are gaining big on the importance of all levels and levels, and interested scientists and specialists in this field, the study proved that there is a disparity in the performance of those hospitals under study and the lack of impact on the environment, whether internal or external. 